\title{
Overweight in childhood and early adulthood is associated with parental Body Mass Index and perinatal risk factors
}

\author{
Konstantinos D. Tambalis ${ }^{1,2}$, Demosthenes B. Panagiotakos ${ }^{1}$, Labros S. Sidossis ${ }^{1,3}$ \\ 'Department of Nutrition and Dietetics, Harokopio University, Athens, Greece \\ ${ }^{2}$ Department of Physical Education and Sport Science, National and Kapodistrian University of Athens, \\ Athens, Greece \\ ${ }^{3}$ Department of Kinesiology and Health, Rutgers University, New Brunswick, USA
}

\section{Corresponding Author}

Konstantinos D. Tambalis, ID: (http://orcid.org/0000-0002-5817-9395), Ph.D. Associate Professor, Department of Physical Education and Sport Science, School of Physical Education and Sport Science, National and Kapodistrian University of Athens, Athens, Greece. 12B 28 ${ }^{\text {th }}$ October Str., Athens 12136, Greece. Tel: +302105811857, e-mail: dp425603@hua.gr.

\section{Abstract}

Background: To investigate the associations of pregnancy and pre-pregnancy parental characteristics on child's weight and progression at the early adulthood.

Material and Methods: A random sample of 5,125 dyads children and their mothers was assessed. Mothers were asked to provide information contained in their medical booklets and pregnancy ultrasound records. With the use of a standardized questionnaire, telephone interviews were carried out for the collection of parental factors and offspring's BMI.

Results: Mother's overweight (including obesity) before pregnancy was found to significantly increase the likelihoods of offspring's overweight (including obesity) at the age of 8-9 years and 15-25 years (odds ratio (OR) 1.97; 95\% confidence interval \%CI: 1.65, 2.30 and OR 2.0; 95\%CI: 1.67, 2.36, respectively). Paternal BMI (OR 1.41; 95\% CI: 1.20-1.62), maternal smoking at pregnancy (OR 1.22; 95\% CI: 1.14-1.30), gestational weight gain (OR 1.44; 95\% CI 1.24-1.66), and gestational hypertension OR 1.30; 95\% CI 1.14-1.49) were also found to significantly increase the odds of children's obesity.

Conclusion: Among prenatal factors considered, mother's pre-pregnancy and father's BMI, GWG, not breastfeeding, smoking in pregnancy and gestational hypertension increased the odds of offspring's overweight/obesity in childhood and early adulthood, even after adjustment for several covariates.

Key words: Prenatal factors, pregnancy, obesity, childhood

\section{Introduction}

In nowadays more than 2 billion adults are overweight, among which approximately 650 million are considered clinically obese ${ }^{1}$. It is estimated that worldwide more than 124 million children and ado- 
lescents were obese in 2016, including 41 million children under the age of 5 years ${ }^{1}$. Moreover, the prevalence of overweight and obesity among children and adolescents has risen dramatically from just $4 \%$ in 1975 to just over $18 \%$ in $2016^{1}$. In 2015 , the prevalence of overweight and obesity among schoolaged children in Greece was $22.2 \%$ and $9.0 \%$ in boys and $21.6 \%$ and $7.5 \%$ in girls, respectively ${ }^{2}$. These rates are among the highest worldwide proposing a dramatic increase (by 52\%) in the prevalence of childhood obesity and overweight the last decades ${ }^{3}$. Childhood obesity is associated with adult excess weight status, the development of metabolic syndrome, diabetes and cardiovascular diseases in later life, and the influence of social and psychological functioning of children ${ }^{4-6}$. Rising rates of childhood obesity highlight the emerging importance of early targeted interventions. For this purpose, it is of great concern to determine how perinatal characteristics could be related to childhood and adulthood obesity. Observational studies over the last 20 year suggest that childhood obesity is associated with specific characteristics of pregnancy such as maternal obesity, gestational weight gain, and infant birth weight, while, it is proposed that gestational weight gain is associated with greater offspring body mass index into early adulthood ${ }^{7-10}$. Gestational Diabetes Melitus (GDM) has also been linked with the promotion of offspring obesity or it purely could be a risk marker for a postnatal insult leading to obesity ${ }^{11,12}$. Other maternal specific factors acting during the sensitive time periods of pre- and postnatal development such as preventing pregnancy-induced hypertension, reducing maternal smoking, increasing breastfeeding and regular consumption of physical activity could be useful for the prevention and treatment of childhood obesity ${ }^{13-15}$. Though the above studies highlight the emerging importance of pregnancy determinants and despite the disturbing rates of obesity reported from several countries, there is a lack of long term epidemiologic data regarding the relationship between the period of pregnancy and maternal characteristics with obesity status in childhood and early adulthood, especially in east European and Mediterranean countries, including Greece.

Thus, the aim of the proposed study is to investigate, the role of pregnancy and pre-pregnancy characteristics on child's weight and progression at the adolescents age, taken into consideration several potential covariates.

\section{Materials and Methods \\ Study design}

Population-based data, derived from 10 national school-based health surveys, from a national database, following an official request to the Greek Ministry of Education. The national database included anthropometric data and information on age, gender, city and area, home address and telephone number, which were collected yearly, at the same time period (spring), from 1997 to 2007, with the exception of 2002, in almost all schools of Primary Education (roughly 85\%); schools that did not participate were from borderland areas, with small numbers of children. Thus, from 1997 to 2007, a total of 651,582 8 - to 9 -year-old children ( $51 \%$ boys and $49 \%$ girls, over $95 \%$ of the total student population) participated in the study. Measurements were performed by two trained Physical Education (PE) teachers in each school. PE teachers followed a specific protocol taught in corresponding seminars held by the Greek General Secretariat of Sports. The same protocol was employed in all schools.

\section{Data extraction}

A sample of 5,500 children $(0.8 \%$ of the entire population) was randomly extracted from the database and their mothers were contacted by telephone. Random extraction was performed through 
statistical software. The number of 5,500 subjects was adequate to achieve statistical power greater or equal to $99 \%$ for evaluating a $0.10 \pm 0.05$ change in the regression coefficients at $5 \%$ significance level of two-sided tested hypotheses. The random sampling was stratified according to the region and place of living (e.g., rural/urban), according to the National Statistical Agency and equally distributed during the study period (i.e., 500 mothers per year). The women that refused to participate in the study were 183 (3.3\%). The sample of mother-child dyads covered all geographical regions of Greece (e.g., mainland Greece and the islands). The information of the proposed protocol was collected through telephone interviews based on the Computer Aided Telephone Interviews (CATI) method. In order to validate the process, 100 face-to-face interviews were conducted to check for discrepancies with the information collected by telephone. No such discrepancies were noted in any of the variables evaluated.

\section{Measurements}

All the necessary information was collected using a standardised questionnaire, named the Childhood Obesity Pregnancy Determinants (ChOPreD) questionnaire, designed and developed with the collaboration of the Harokopio University Department of Nutrition \& Dietetics and Department of Geography and the University Of Texas Medical Branch Department Of Internal Medicine. The ChOPreD questionnaire was tested and internally revised by study's investigators during a pilot study, which confirmed its construct validity. During data collection, the mothers were asked to provide information contained in the children's birth certificates, their medical booklets and pregnancy ultrasound records (e.g., body weight, height) and recall certain information (e.g., breastfeeding, smoking patterns, alcohol consumption, educational status, etc). Mothers in Greece have ultrasounds at the start of the pregnancy and several times during its progress and receive records of the results. Only mothers that had full set of records were included in the study, which finalized the sample of 5,125 mother-children dyads. The BMI data for the children at the age of 8 years was calculated based on data retrieved from the national database. The BMI data for the offspring at the age of 2 was determined from anthropometric data reported from the health books. The paternal BMI data and the BMI data for the offspring at the ages of 15-25 were self-reported. The parental and the offspring BMI status were calculated as the ratio of body weight to the square of height $(\mathrm{kg} / \mathrm{m} 2)$ based on cut-off points suggested by Cole and his colleagues ${ }^{16}$. Gestational Weight Gain was calculated based on the difference between the mother's body weight at the last and first visits, based on ultrasound records. Each mother GWG was categorized according to the Institute of Medicine (IOM) guidelines ${ }^{17}$.

\section{Prenatal determinants}

Prenatal and neonatal data such as maternal age, nationality, pregnancy in vitro and parity before were extracted from medical booklets and pregnancy ultrasound records. Data recall relating to the perinatal period is very common in pregnancy-related studies ${ }^{18}$. Specifically, mothers were asked whether their child was born on the projected birth date or, if not, how many days earlier or later. Preterm birth was determined as the birth of an infant child at fewer than 37 weeks' gestational age ${ }^{19}$. The number of births before or after the birth of the child taking part in the research was also required. The questionnaire also required clarification whether pregnancy was the result of an IVF (In Vitro Fertilization), as this may correlate with diseases or pregnancy abnormalities.

\section{Maternal pregnancy conditions}

Mothers were asked about probable abnormalities and diseases before and during pregnancy 
(preeclampsia - hypertension and proteinouria or eclampsia-preeclampsia plus convulsions), as well as any history of diabetes or hypertension and whether they had diabetes or hypertension during pregnancy. Also, mothers were asked if they smoked during pregnancy, and if so, the number of cigarettes smoked daily and if they consumed alcohol during pregnancy, and how many glasses of alcohol they consumed per week as well as which, if any, narcotic drugs they took.

\section{Study approval}

The study was approved by the Bioethics Committee of Harokopio University. Oral approval was obtained from all mothers who agreed to participate in the study and written. Informed consent was obtained from those participants who took part in the validation process of the study.

\section{Statistical Analysis}

Continuous variables were presented as mean values \pm standard deviations (SD) given that they were normally distributed (as examined by the use of histograms and P-P plots). Categorical variables were presented as frequencies. The chi-square test evaluated associations between the categorical variables and the Student's t test were applied to evaluate differences in mean values of normally distributed variables. In order to assess the potential relationships between parental BMI (as continuous variables) with offspring's BMI in several ages we applied linear regression analysis taking into consideration several covariates (offspring's sex, gestational age, nationality, area of living, mode of delivery, pregnancy on time, educational status, exercise during pregnancy, gestational diabetes and hypertension, alcohol consumption during pregnancy and smoking during pregnancy). Prior to that, every possible effect modification between the proposed risk factors and the confounders was examined, but all interaction terms were not statistical significant ( $p$-values $>0.05$ ).
Furthermore, aiming to assess the potential effect of perinatal characteristics on offspring's BMI status (normalweight vs. overweight/obese) binary logistic regression analyses was implemented and OR with the corresponding 95\% CI was calculated, while controlling for confounding. The Hosmer and Lemeshow's goodness-of-fit test was calculated in order to evaluate the model's goodness-of-fit and residual analysis was implicated using the dbeta, the leverage, and Cook's distance D statistics in order to identify outliers and influential observations. Discriminant analysis was applied to investigate the strength of each component concerning the outcome. All analyses were performed using the SPSS version 23.0 software for Windows (SPSS Inc., Chicago, IL, USA). Statistical significance level from two-sided hypotheses was set at the $5 \%$ level $(p \leq 0.05)$

\section{Results}

A percentage of $3.3 \%$ of mothers did not agree to participate in the current study, while of those participated, a proportion of $3.5 \%$ did not have a full set of data. Paternal, maternal, and offspring characteristics of the study sample are presented in Table 1. Results from linear regression analysis revealed that maternal pre-pregnancy BMI, maternal BMI at the end of pregnancy and paternal BMI were positively associated with offspring's birth weight and BMI at age of 2, 8-9 and 15-25 years (Table 2, Model 1), in unadjusted models (all P-values<0.05). For example, each $\mathrm{kg} / \mathrm{m} 2$ increase in mppBMI was associated with a $0.18 \mathrm{~kg} / \mathrm{m} 2$ increase in offspring BMI at the age of 8-9 years (95\% CI: 0.08 to 0.28 , $\mathrm{P}<0.001)$. The associations remained significant after adjustment for children's sex, gestational age, mother's nationality and area of living, mode of delivery, pregnancy on time, educational status, and exercise during pregnancy, gestational diabetes, gestational hypertension, alcohol consumption and smoking during pregnancy (Table 2, Model 2). Hierarchical 
Table 1. Characteristics of the studied sample of parents and their offspring.

\begin{tabular}{|c|c|c|c|}
\hline \multicolumn{2}{|l|}{ OFFSPRING CHARACTERISTICS } & \multicolumn{2}{|l|}{ PHYSICAL ACTIVITY LEVELS } \\
\hline Males, n (\%) & $2686(52.4 \%)$ & Never, n (\%) & $3303(64.5)$ \\
\hline Females, n (\%) & $2439(47.5 \%)$ & Moderate, n (\%) & $858(16.7)$ \\
\hline Age (years) & $8.5(0.5)$ & Sometimes/often, $\mathrm{n}(\%)$ & $966(15.8)$ \\
\hline Birth Weight, Kg & $3.33(0.5)$ & Breastfeeding (months) & $3.2(4.0)$ \\
\hline BMI at Birth, $\mathrm{Kg} / \mathrm{m}^{2}$ & $12.6(1.7)$ & Smoking during pregnancy, n (\%) & $588(11.5)$ \\
\hline BMI at Age 2 (infant), $\mathrm{Kg} / \mathrm{m}^{2}$ & $16.5(2.4)$ & Yes $\quad 588(11.5 \%)$ & \\
\hline BMI at Age 8 years, $\mathrm{Kg} / \mathrm{m}^{2}$ & $17.6(3.0)$ & \multicolumn{2}{|l|}{$\begin{array}{c}\text { No } 4537(88.5 \%) \\
\text { Alcohol consumption, } \mathrm{n}(\%)\end{array}$} \\
\hline BMI at follow-up (15-25-y-old), $\mathrm{Kg} / \mathrm{m}^{2}$ & \multirow[t]{2}{*}{$22.6(3.5)$} & $\begin{array}{l}\text { Alconol consumption, } \mathrm{n}(\%) \\
\text { Yes } 476(9.3 \%)\end{array}$ & \\
\hline MATERNAL CHARACTERISTICS & & No $\quad 4649(90.7 \%)$ & \\
\hline Maternal Age at Pregnancy, (years) & $27.9(4.8)$ & Drugs during pregnancy, n (\%) & $6(0.2)$ \\
\hline Greek nationality, n (\%) & $4792(93.5)$ & Alcohol consumption during pregnancy, n(\%) & $476(9.3)$ \\
\hline \multirow{2}{*}{ Gestational age (weeks) } & ) & Diabetes during pregnancy, $\mathrm{n}(\%)$ & $97(1.9)$ \\
\hline & $39.2(1.6)$ & Yes $\quad 588(11.5 \%)$ & \\
\hline Pregnancy in vitro, n (\%) & $52(1.3)$ & No $\quad 4537(88.5 \%)$ & \\
\hline Bedtime during pregnancy, n (\%) & $80(1.6)$ & \multicolumn{2}{|l|}{ Alcohol consumption, $\mathrm{n}(\%)$} \\
\hline Parity before, $\mathrm{n}(\%)$ & $2528(49.7)$ & Yes $\quad 476(9.3 \%)$ & \\
\hline BMI in first visit, $\mathrm{Kg} / \mathrm{m}^{2}$ & $22.5(3.2)$ & \multicolumn{2}{|l|}{ No $\quad 4649(90.7 \%)$} \\
\hline $\mathrm{BMI}$ in last visit, $\mathrm{Kg} / \mathrm{m}^{2}$ & $27.8(3.9)$ & Hypertension during pregnancy, n(\%) & $118(2.3)$ \\
\hline BMI at follow-up, $\mathrm{Kg} / \mathrm{m}^{2}$ & $26.0(4.5)$ & \multirow{2}{*}{ PARENTAL CHARACTERISTICS } & \\
\hline \multirow[t]{2}{*}{ Gestational weight gain (GWG), Kg } & $14.3(3.5)$ & & \\
\hline & & $\mathrm{BMI}, \mathrm{Kg} / \mathrm{m}^{2}$ & $27.7(3.7)$ \\
\hline EDUCATIONAL STATUS & & Educational status & \\
\hline Basic $(\leq 6$ years $)(\%)$ & 23.4 & Basic $(\leq 6$ years) $(\%)$ & 31.8 \\
\hline Secondary $(\leq 12$ years) $(\%)$ & 44.4 & Secondary ( $\leq 12$ years) $(\%)$ & 40.8 \\
\hline Higher (> 12 years) $(\%)$ & 32.2 & Higher (> 12 years) (\%) & 27.4 \\
\hline
\end{tabular}

binary logistic regression analysis was applied to explore the independent effect of several perinatal characteristics (e.g. maternal pre-pregnancy BMI status, GWG, paternal BMI status, breastfeeding, type of conception, gestational age, hypertension, smoking, diabetes and alcohol consumption during pregnancy) on offspring's overweight (normalweight vs. overweight/obese). The initial univariate analysis (Table 3 , Model 1) showed that mother's overweight/obesity before pregnancy was associated with 2.03 (95\% CI: $1.75,2.36$ ) and 2.20 (95\%CI: 1.86, 2.60)-times higher odds of the offspring being overweight/obese at the age of 8-9 years and 15-25 years, respectively. Moreover, paternal overweight/obesity, excess GWG,

not breastfeeding, smoking during pregnancy and gestational diabetes and gestational hypertension were also associated with increased odds of offspring's overweight/obesity in childhood. When all predictors included in the analysis (Table 3, Model 2 ), the previous findings did not alter significantly (with the exception of gestational diabetes), while, after additional adjustment for offspring's sex, birth weight, maternal age at pregnancy, nationality, area of living and educational status, and pregnancy on time and mode of delivery (Table 3, Model 3), the results remained statistically significant.

Discriminant analysis was conducted to evaluate whether the perinatal predictors could bet- 
Table 2. Results of linear regression models of the association of parental BMI with offspring BMI at different ages.

\begin{tabular}{|c|c|c|c|c|c|}
\hline & & Predictors & $b \pm S E$ & Beta & $\mathbf{p}$ \\
\hline \multirow[t]{12}{*}{ Model 1} & \multirow[t]{3}{*}{ Age 0 (newborn) } & MppBMI, per $1 \mathrm{~kg} / \mathrm{m}^{2}$ & $0.04 \pm 0.01$ & 0.07 & $<0.001$ \\
\hline & & MfinalBMI, per $1 \mathrm{~kg} / \mathrm{m}^{2}$ & $0.05 \pm 0.01$ & 0.11 & $<0.001$ \\
\hline & & PBMI, per $1 \mathrm{~kg} / \mathrm{m}^{2}$ & $0.02 \pm 0.01$ & 0.04 & 0.008 \\
\hline & \multirow[t]{3}{*}{ Age 2 (infant) } & MppBMI, per $1 \mathrm{~kg} / \mathrm{m}^{2}$ & $0.03 \pm 0.01$ & 0.07 & 0.005 \\
\hline & & MfinalBMI, per $1 \mathrm{~kg} / \mathrm{m}^{2}$ & $0.06 \pm 0.02$ & 0.10 & $<0.001$ \\
\hline & & PBMI, per $1 \mathrm{~kg} / \mathrm{m}^{2}$ & $0.04 \pm 0.02$ & 0.07 & 0.007 \\
\hline & \multirow[t]{3}{*}{ Age 8 (child) } & MppBMI, per $1 \mathrm{~kg} / \mathrm{m}^{2}$ & $0.17 \pm 0.01$ & 0.18 & $<0.001$ \\
\hline & & MfinalBMI, per $1 \mathrm{~kg} / \mathrm{m}^{2}$ & $0.15 \pm 0.01$ & 0.18 & $<0.001$ \\
\hline & & PBMI, per $1 \mathrm{~kg} / \mathrm{m}^{2}$ & $0.10 \pm 0.01$ & 0.13 & $<0.001$ \\
\hline & \multirow[t]{3}{*}{ Age 15-25 (early adulthood) } & MppBMI, per $1 \mathrm{~kg} / \mathrm{m}^{2}$ & $0.23 \pm 0.02$ & 0.21 & $<0.001$ \\
\hline & & MfinalBMI, per $1 \mathrm{~kg} / \mathrm{m}^{2}$ & $0.21 \pm 0.01$ & 0.24 & $<0.001$ \\
\hline & & PBMI, per $1 \mathrm{~kg} / \mathrm{m}^{2}$ & $0.16 \pm 0.01$ & 0.17 & $<0.001$ \\
\hline \multirow[t]{12}{*}{ Model 2} & \multirow[t]{3}{*}{ Age 0 (newborn) } & MppBMI, per $1 \mathrm{~kg} / \mathrm{m}^{2}$ & $0.05 \pm 0.01$ & 0.08 & $<0.001$ \\
\hline & & MfinalBMI, per $1 \mathrm{~kg} / \mathrm{m}^{2}$ & $0.05 \pm 0.01$ & 0.11 & $<0.001$ \\
\hline & & PBMI, per $1 \mathrm{~kg} / \mathrm{m}^{2}$ & $0.02 \pm 0.01$ & 0.04 & 0.018 \\
\hline & \multirow[t]{3}{*}{ Age 2 (infant) } & MppBMI, per $1 \mathrm{~kg} / \mathrm{m}^{2}$ & $0.03 \pm 0.01$ & 0.08 & 0.015 \\
\hline & & MfinalBMI, per $1 \mathrm{~kg} / \mathrm{m}^{2}$ & $0.05 \pm 0.02$ & 0.08 & 0.004 \\
\hline & & PBMI, per $1 \mathrm{~kg} / \mathrm{m}^{2}$ & $0.04 \pm 0.02$ & 0.07 & 0.007 \\
\hline & \multirow[t]{3}{*}{ Age 8 (child) } & MppBMI, per $1 \mathrm{~kg} / \mathrm{m}^{2}$ & $0.20 \pm 0.02$ & 0.20 & $<0.001$ \\
\hline & & MfinalBMI, per $1 \mathrm{~kg} / \mathrm{m}^{2}$ & $0.15 \pm 0.01$ & 0.20 & $<0.001$ \\
\hline & & PBMI, per $1 \mathrm{~kg} / \mathrm{m}^{2}$ & $0.10 \pm 0.01$ & 0.12 & $<0.001$ \\
\hline & \multirow[t]{3}{*}{ Age 15-25 (early adulthood) } & MppBMI, per $1 \mathrm{~kg} / \mathrm{m}^{2}$ & $0.23 \pm 0.02$ & 0.20 & $<0.001$ \\
\hline & & MfinalBMI, per $1 \mathrm{~kg} / \mathrm{m}^{2}$ & $0.21 \pm 0.02$ & 0.25 & $<0.001$ \\
\hline & & PBMI, per $1 \mathrm{~kg} / \mathrm{m}^{2}$ & $0.14 \pm 0.02$ & 0.15 & $<0.001$ \\
\hline
\end{tabular}

MppBMI: maternal pre-pregnancy body mass index; MfBMI: maternal final body mass index; PBMI: paternal body mass index. Model 1: unadjusted

Model 2: adjusted for sex, age, nationality, gestational age, mode of delivery, pregnancy on time, type of conception, educational status, exercise during pregnancy, gestational diabetes, gestational hypertension, alcohol consumption during pregnancy and smoking during pregnancy

ter distinguish offspring's BMI status in childhood (normalweight vs. overweight/obese). Standardized function coefficients suggest that maternal BMI before pregnancy (0.78), GWG (0.40), paternal BMI status (0.32) and smoking during pregnancy $(0.28)$ contribute more to distinguishing offspring's BMI status in childhood. The classification results show that the model correctly predicts $74 \%$ of normalweight and $61 \%$ of overweight/obese.

\section{Discussion}

To the extent that we know the current study is among the few studies aimed to investigate the potential association of several perinatal predictors on offspring's overweight/obesity. Specifically, although there is plenty of scientific literature regarding the effect of perinatal factors per se on childhood overweight/obesity, there are only two previous studies exploring the independent effect of all these 
Table 3. Results (OR, 95\%CI, p) from logistic regression models that used to evaluate the association of perinatal characteristics with offspring BMI status (normal weight vs. overweight/obesity) at childhood and early adulthood.

\begin{tabular}{|c|c|c|c|}
\hline PREDICTORS & $\begin{array}{l}\text { UNIVARIATE MODELS } \\
\text { OR } 95 \% \text { CI }\end{array}$ & $\begin{array}{l}\text { FULL MODEL } \\
\text { OR } 95 \% \text { CI }\end{array}$ & $\begin{array}{c}\text { FULL MODEL, PLUS } \\
\text { CONFOUNDERS }^{3} \\
\text { OR } 95 \% \text { CI }\end{array}$ \\
\hline \multicolumn{4}{|l|}{ CHILD (8-9 YEARS) } \\
\hline MppBMI, (normalweight vs. overweight/obese) & $2.03(1.75-2.36)$ & $2.01(1.72-2.35)$ & $1.97(1.65-2.30)$ \\
\hline PBMI, (normalweight vs. overweight/obese) & $1.46(1.25-1.70)$ & $1.43(1.22-1.65)$ & $1.41(1.20-1.62)$ \\
\hline Gestational weight gain (adequate vs. Excess) & $1.45(1.26-1.67)$ & $1.44(1.24-1.66)$ & $1.44(1.24-1.66)$ \\
\hline Exclusive breastfeeding $\geq 6$ months (Yes vs. No) & $1.30(1.21-1.42)$ & $1.30(1.20-1.42)$ & $1.28(1.17-1.40)$ \\
\hline Type of conception (normal vs. in vitro fertilization) & $1.58(0.81-3.01)$ & $1.53(0.82-2.49)$ & $1.48(0.77-2.40)$ \\
\hline Gestational age ( $<37$ vs. $\geq$ weeks) & $1.12(0.99-1.26)$ & $1.11(0.92-1.21)$ & $1.08(0.87-1.20)$ \\
\hline Smoking status during pregnancy (No vs. Yes) & $1.21(1.13-1.29)$ & $1.21(1.15-1.27)$ & $1.22(1.14-1.30)$ \\
\hline Alcohol during pregnancy (No vs. Yes) & $1.03(0.84-1.27)$ & $1.01(0.80-1.32)$ & $1.02(0.82-1.29)$ \\
\hline Diabetes during pregnancy (No vs. Yes) & $1.23(1.08-1.45)$ & $1.12(0.81-1.44)$ & $1.12(0.88-1.38)$ \\
\hline Hypertension during pregnancy (No vs. Yes) & $1.33(1.14-1.57)$ & $1.31(1.11-1.55)$ & $1.30(1.14-1.49)$ \\
\hline \multicolumn{4}{|l|}{ EARLY ADULTHOOD (15-25 YEARS) } \\
\hline MppBMI, (normalweight vs. overweight/obese) & $2.20(1.86-2.60)$ & $2.20(1.78-2.72)$ & $2.00(1.63-2.67)$ \\
\hline PBMI, (normalweight vs. overweight/obese) & $1.60(1.33-1.93)$ & $1.57(1.24-1.98)$ & $1.37(1.14-1.68)$ \\
\hline Gestational weight gain (adequate vs. excess) & $1.51(1.32-1.71)$ & $1.41(1.22-1.61)$ & $1.24(1.07-1.45)$ \\
\hline Exclusive breastfeeding $\geq 6$ months (Yes vs. No) & $1.30(1.08-1.58)$ & $1.44(1.17-1.78)$ & $1.49(1.17-1.90)$ \\
\hline Type of conception (normal vs. in vitro fertilization) & $1.47(0.75-2.45)$ & $1.33(0.75-2.09)$ & $1.38(0.67-2.19)$ \\
\hline Gestational age (<37 vs. $\geq$ weeks $)$ & $1.09(0.88-1.29)$ & $1.10(0.89-1.22)$ & $1.07(0.85-1.24)$ \\
\hline Smoking status during pregnancy (No vs. Yes) & $1.07(0.89-1.35)$ & $1.05(0.92-1.42)$ & $1.19(1.01-1.48)$ \\
\hline Alcohol during pregnancy (No vs. Yes) & $1.38(1.08-1.86)$ & $1.48(1.04-2.12)$ & $1.72(1.12-2.63)$ \\
\hline Diabetes during pregnancy (No vs. Yes) & $1.11(0.65-1.88)$ & $1.27(0.58-2.76)$ & $1.38(1.07-2.14)$ \\
\hline Hypertension during pregnancy (No vs. Yes) & $1.22(0.92-1.51)$ & $1.17(0.84-1.55)$ & $1.26(0.86-1.66)$ \\
\hline
\end{tabular}

${ }^{1}$ The effect of each predictor on the offspring BMI status was separately evaluated;

${ }^{2}$ Includes all predictors (i.e maternal pre-pregnancy body mass index, paternal body mass index, gestational weight gain, exclusive breastfeeding, type of conception, gestational age, alcohol consumption, smoking, gestational diabetes and gestational hypertension on offspring obesity status);

${ }^{3}$ Includes all predictors entered in the full model plus sex, birth weight, maternal age at pregnancy, nationality, area of living, educational status, exercise status, parity before and mode of delivery, as potential confounders.

variables ${ }^{20,21}$. Findings from this representative cohort showed that (a) maternal pre-pregnancy BMI, maternal BMI at the end of pregnancy and paternal BMI were positively associated with offspring's birth weight and BMI at childhood and early adulthood, and (b) breastfeeding, smoking during pregnancy and gestational hypertension were also associated with increased odds of offspring's overweight/obesity in childhood, even after adjusting for several covariates.

In accordance with previous findings, the current study revealed that offspring having overweight/ obese mother and/or father parents had enlarged odds of being overweight/obese in childhood and in early adulthood ${ }^{21-23}$. In details the results showed 
mother's and father's overweight/obesity were associated with 1.97 (95\%CI: 1.65, 2.30) and 1.40 (95\%CI: $1.20,1.62)$-times higher odds of the offspring childhood overweight/obese, respectively, even after adjusting for several covariates. Recent meta-analysis revealed a strong parental-child (P-C) obesity association (OR: 2.22; 95\% CI: 2.09, 2.36), which varied by type of P-C pair (i.e., father-child, and mother-child), child age, parent and child BMI status $^{24}$. A family history of overweight or/and obesity is a significant factor of the genetic risk for childhood or/and adulthood overweight ${ }^{25}$. Nevertheless, above and beyond inheritance of genes that confer vulnerability to childhood overweight, during this timeperiod, parental influence and role modeling play a key part in the development of unhealthy behaviors such as consumption of energy-dense foods and beverages, sedentary behavior and physical inactivity ${ }^{26,}$ 27. Specifically, it is common phenomenon overweight parents to create and maintain an 'obesogenic' environment not only for themselves but also for their offsprin ${ }^{28}$. All the same, the etiology of childhood overweight/obesity seems to be more multifaceted than the environment a child grows up. Also, the analysis indicated that excess GWG was associated with 1.44-times higher odds of the offspring being overweight/obese $(95 \% \mathrm{CI}: 1.24,1.64)$ at the age of 8 to 9 years as compared with offspring of women with adequate GWG. Similarly, several studies reported that excess GWG independently could be associated with the development of childhood obesity, while, GWG has also been associated with increased offspring BMI in childhood and early adulthood ${ }^{7-10}$.

Regarding the influence of breastfeeding on offspring's BMI status, this data showed that non breast feeders was associated with greater odds of overweight/obesity at the childhood as well as during adolescence/adulthood, as compared to exclusive breastfeeding $>6$ months. Numerous meta-analyses support the favorable effect of breastfeeding on body composition across the life ${ }^{18,29-30}$. Moreover, metaanalysis indicated that the decrease in the risk of childhood overweight/obesity of offspring who fed relative to those who did not feed was $15 \%{ }^{31}$, while, another meta-analysis concluded that children who had breastfed presented $22 \%$ lower obesity risk as compared to those who had not ${ }^{10}$.

Among many other potential adverse effects of maternal smoking on offspring health, it is considered that increases the risk for overweight/obesity at the childhood and young adulthood, while it is straightforwardly associated with higher fat mass and lower birth weight ${ }^{32,33}$. The present data revealed that mother's smoking during pregnancy was associated with 1.22 (95\%CI: 1.14, 1.30)-times increased odds of the offspring childhood overweight/obesity. In line with the results of the present study, several epidemiological studies have also confirmed an association between maternal smoking during pregnancy and childhood overweight/obesity ${ }^{34,35}$. The underlying mechanism of this association even now stays ambiguous. A potential explanation could be that maternal smoking during pregnancy is another proxy for factors exist in the offspring's postnatal familial habitat, such as unhealthy dietary habits and inadequate physical activity levels ${ }^{34}$.

Our results reported a positive effect of maternal's gestational diabetes on childhood overweight/ obesity. This association was no longer present after adjustment for maternal pre-pregnancy BMI. Previous systematic reviews proposed that gestational diabetes was associated with a higher offspring BMI, while, associations did not exist in single studies that adjusted for maternal pre-pregnancy $\mathrm{BMI}^{36,37}$. Moreover, recent meta-analysis found that gestational diabetes was associated with higher odds of overweight throughout childhood as compared to uncomplicated pregnancies, but the associations attenuated towards the null following adjustment for maternal $\mathrm{BMI}^{38}$. 
Finally, our findings speculated that hypertension during pregnancy was associated with 30\% higher odds of childhood overweight/obesity in comparison with uncomplicated pregnancies. In accordance with previous findings, a United Kingdom study reported that children of women who had gestational hypertension had higher risk of obesity at 9 years, whereas an Australian study showed similar associations in term born young adults of mothers with gestational hypertension ${ }^{39,40}$. Likewise, meta- analysis reported that gestational hypertension was associated with higher probabilities of overweight throughout childhood, when compared to uncomplicated pregnancies, but further adjustment for maternal BMI largely explained the associations ${ }^{38}$.

In view of the fact that several prenatal factors such as BMI and not smoking are modifiable, health care professionals such as doctors, physicians, midwifes, teachers and persons involved in maternal healthcare and information should recommend prospective mothers to take care for their health choosing a healthier lifestyle and avoiding overweight and smoking.

The most significant strengths of this study were: (a) it examined the possible association between numerous perinatal factors and overweight in various stages of offspring's life considering a large, representative sample equally distributed (about 500 dyads per year) throughout the study period (1997-2007); (b) a well-balanced sex distribution; and (c) an adjustment for several factors that possibly confound the association of the above factors with childhood overweight as it focused on the intricacy of factors that interact in the development of childhood overweight.

The information that was collected during the telephone interviews was self-reported. Consequently, although mothers could provide information derived from health records for themselves, this consists in a limitation of the study. Particularly, this could be attributed to deliberate over-reporting, underreporting, or recall bias for the self-reported prepregnancy data.

\section{Conclusions}

Results from our analysis demonstrated that mother's pre-pregnancy BMI, GWG, not breastfeeding, smoking during pregnancy and gestational hypertension and father's BMI were associated with higher odds of offspring's overweight/obesity in childhood and early adulthood, even after adjustment for several covariates.

\section{Acknowledgments}

The authors want to thank the study subjects for their willingness to participate.

\section{References}

1. World Health Organization. World Obesity. Prevalence of Obesity. https://www.worldobesity.org/ about/about-obesity/prevalence-of-obesity. Assessed 20 Feb 2021.

2. Tambalis KD, Panagiotakos DB, Psarra G, Sidossis LS. Current data in Greek children indicate decreasing trends of obesity in the transition from childhood to adolescence; results from the EYZHN (National Action for Children's Health) program". Journal of Preventive Medicine and Hygiene 2018; 59:E40-E51.

3. Tambalis KD, Panagiotakos DB, Kavouras SA, et al. Eleven-year Prevalence Trends of Obesity in Greek Children: First Evidence that Prevalence of Obesity Is Leveling Off. Obesity (Silver Spring) 2010; 18(1):161-6.

4. Power C, Lake JK, Cole TJ. Measurement and longterm health risks of child and adolescent fatness. Inl J Obes 1997; 21:507-26.

5. Williams J, Wake M, Hesketh K, Maher E, Waters E. Health-related quality of life of overweight and obese children. JAMA 2005; 293:70-6. 
6. Reilly JJ, Methven E, McDowell ZC, et al. Health consequences of obesity. Arch Dis Child 2003; 88:748-52.

7. Rooney BL, Mathiason MA, Schauberger CW. Predictors of obesity in childhood, adolescence, and adulthood in a birth cohort. Matern Child Health J 2011; 15(8):1166-75.

8. Mamun AA, Callaway LK, O'Callaghan MJ, et al. Associations of maternal pre-pregnancy obesity and excess pregnancy weight gains with adverse pregnancy outcomes and length of hospital stay. BMC Pregnancy Childbirth 2011; 11:62.

9. Schack-Nielsen l, Michaelsen KF, Gamborg M, Mortensen EL, Sorensen TI. Gestational weight gain in relation to offspring body mass index and obesity from infancy through adulthood. Int J Obes (Lond) 2010; 34(1):67-74.

10. Arenz S, Von Kries R. Protective effect of breastfeeding against obesity in childhood: can a metaanalysis of published observational studies help to validate the hypothesis? Adv Exp Med Biol 2009; 639:145-52. Review.

11. Levin BE. Synergy of nature and nurture in the development of childhood obesity. Int J Obes (Lond) 2009; 33 Suppl 1:S53-6.

12. Gillman MW, Rifas-Shiman S, Berkley CS, Field AE, Colditz GA. Maternal gestational diabetes, birth weight, and adolescent obesity. Pediatrics 2003; 111(3):e221-6.

13. Lawlor DA, Smith GD. Early life determinants of adult blood pressure. Curr Opin Nephrol Hypertens 2005; 14(3):259-64.

14. Melzer K, Schutz Y, Boulvain M, Kayser B. Physical activity and pregnancy: cardiovascular adaptations, recommendations and pregnancy outcomes. Sports Med 2010; 40(6):493-507.

15. Feid DS, Lipscomble LL, Tomlinson G, Blumer I. Breastfeeding predicts the risk of childhood obesity in a multi-ethnic cohort women with diabetes. J Matern Fetal Neonatal Med 2011; 24(3):511-5.
16. Cole TJ, Flegal KM, Nicholls D, Jackson AA. Body mass index cut offs to define thinness in children and adolescents: international survey. BMJ 2007 28; 335(7612):194.

17. Khanolkar AR, Hanley GE, Koupil I, Janssen PA. 2009 IOM guidelines for gestational weight gain: how well do they predict outcomes across ethnic groups? Ethn Health 2020; 25(1):110-25.

18. Li R, Scanlon KS, Serdula MK. The validity and reliability of maternal recall of breastfeeding practice. Nutrition Reviews 2005; 63(4):103-10.

19. World Health Organization (WHO). Preterm birth. https://www.who.int/news-room/fact-sheets/detail/preterm-birth. Assessed 20 Feb 2021.

20. Gopinath B, Baur LA, Burlutsky G, Robaei D, Mitchell P. Socio-economic, familial and perinatal factors associated with obesity in Sydney schoolchildren. J Paediatr Child Health 2012; 48(1):44-51.

21. Birbilis M, Moschonis G, Mougios V, Manios Y; Healthy Growth Study' group. Obesity in adolescence is associated with perinatal risk factors, parental BMI and sociodemographic characteristics. Eur J Clin Nutr 2013; 67(1):115-21.

22. Kollias AK, Skliros EA, Leotsakos N, Gikas A, Garifallos D. Childhood obesity in relation to parental weight status in Greece. Hippokratia 2009; 13:253.

23. Ness AR. The Avon Longitudinal Study of Parents and Children (ALSPAC) - a resource for the study of the environmental determinants of childhood obesity. Eur J Endocrinol 2004; 151 (Suppl 3):U141-9.

24. Wang Y, Min J, Khuri J, Li M. A Systematic Examination of the Association between Parental and Child Obesity across Countries. Adv Nutr 2017; 8(3):436-48.

25. Yang W, Kelly T, He J. Genetic epidemiology of obesity. Epidemiol Rev 2007; 29:49-61.

26. Niemeier BS, Hektner JM, Enger KB. Parent participation in weight-related health interventions for children and adolescents: a systematic review and meta-analysis. Prev Med 2012; 55(1):3-13. 
27. Natale RA, Messiah SE, Asfour L, Uhlhorn SB, Delamater A, Arheart KL. Role modeling as an early childhood obesity prevention strategy: effect of parents and teachers on preschool children's healthy lifestyle habits. J Dev Behav Pediatr 2014; 35(6):378-87.

28. Whitaker RC. Predicting preschooler obesity at birth: the role of maternal obesity in early pregnancy. Pediatrics 2004; 114:e29-e36.

29. Sherry B, Jefferds ME, Grummer-Strawn LM. Accuracy of adolescent self-report of height and weight in assessing overweight status: A literature review. Arch Pediatr Adolesc Med 2007; 161:1154-61.

30. Owen CG, Martin RM, Whincup PH, et al. Effect of infant feeding on the risk of obesity across the life course: A quantitative review of published evidence. Pediatrics 2005; 115:1367-77.

31. Owen CG, Martin RM, Whincup PH, et al. The effect of breastfeeding on mean body mass index throughout life: A quantitative review of published and unpublished observational evidence. Am J Clin Nutr 2005; 82:1298-1307.

32. Oken E, Levitan EB, Gillman MW. Maternal smoking during pregnancy and child overweight: systematic review and meta analysis. Int J Obes (Lond) 2008; 32:201-10.

33. Mund M, Louwen F, Klingelhoefer D, Gerber A. Smoking and pregnancy-A review on the first major environmental risk factor of the unborn. Int J Environ Res Public Health 2013; 10:6485-99.

34. Power C, Jefferis BJ. Fetal environment and subsequent obesity: a study of maternal smoking. Int J Epidemiol 2002; 31:413-9.
35. von Kries R, Toschke AM, Koletzko B, Slikker Jr W. Maternal smoking during pregnancy and childhood obesity. Am J Epidemiol 2002; 156:954-61.

36. Kim SY, England JL, Sharma JA, Njoroge T. Gestational diabetes mellitus and risk of childhood overweight and obesity in offspring: a systematic review. Exp Diabetes Res 2011; 2011:541308.

37. Philipps LH, Santhakumaran S, Gale C, et al. The diabetic pregnancy and offspring BMI in childhood: a systematic review and meta-analysis. Diabetologia 2011; 54(8):1957-66.

38. Patro Golab B, Santos S, Voerman E, et al. Influence of maternal obesity on the association between common pregnancy complications and risk of childhood obesity: an individual participant data meta-analysis. Lancet Child Adolesc Health 2018; 2(11):812-21.

39. Geelhoed JJ, Fraser A, Tilling K, Benfield L, et al. Preeclampsia and gestational hypertension are associated with childhood blood pressure independently of family adiposity measures: the Avon Longitudinal Study of Parents and Children. Circulation 2010; 122(12):1192-9.

40. Davis EF, Lewandowski AJ, Aye C, Clinical cardiovascular risk during young adulthood in offspring of hypertensive pregnancies: insights from a 20year prospective follow-up birth cohort. BMJ Open 2015; 5(6):e008136.
Received 10-03-21

Revised 16-03-21

Accepted 23-03-21 
